\title{
On the Basis of Moral Equality: a Rejection of the Relation-First Approach
}

\section{Giacomo Floris ${ }^{1}$ (D)}

Accepted: 1 March 2019 / Published online: 26 March 2019

(C) The Author(s) 2019

\begin{abstract}
The principle of moral equality is one of the cornerstones of any liberal theory of justice. It is usually assumed that persons' equal moral status should be grounded in the equal possession of a status-conferring property. Call this the property-first approach to the basis of moral equality. This approach, however, faces some well-known difficulties: in particular, it is difficult to see how the possession of a scalar property can account for persons' equal moral status. A plausible way of circumventing such difficulties is to explore another avenue for the justification of persons' equal moral status: moral equality should be grounded in the wrongness of treating others as inferiors. Call this the relation-first approach to the basis of moral equality. This paper aims at providing some reasons as to why this approach should be rejected and clarifying why the property-first approach still represents the most promising way of justifying our commitment to moral equality. Two objections will be pressed against the relation-first approach: first, grounding moral equality in the wrongness of treating others as inferiors gives rise to some disturbing normative implications; second, relation-first accounts cannot vindicate the idea that a range of beings has equal fundamental rights. This, however, is precisely what an account of moral equality is meant to justify. The paper, then, concludes that the relation-first approach fails to provide a plausible answer to the question of the basis of moral equality. Property-first accounts, whatever problems they encounter, are still more viable in principle.
\end{abstract}

Keywords Moral equality $\cdot$ Moral status $\cdot$ Relational normativity $\cdot$ Rights $\cdot$ Sangiovanni

\section{Introduction}

The question of the basis of moral equality is central to moral and political philosophy: accordingly, many have attempted to find a justification as to why persons are moral equals.

Giacomo Floris

giacomo.floris@manchster.ac.uk

1 University of Manchester, Oxford Road, Manchester M13 9PL, UK 
And, while there are different views on which exact basis is meant to ground persons' equal moral status, the whole debate seems to take for granted that there is only one promising approach to the question of the basis of moral equality. Traditionally, accounts of moral equality have proceeded as follows: 1) a property $\mathrm{X}$ that confers moral status is identified; 2) those beings that equally possess $X$ can be said to have equal moral status; 3 ) hence, equal moral status is grounded in the equal possession of $\mathrm{X}$. Call this the property-first approach to the basis of moral equality. ${ }^{1}$ As many have noted, however, the property-first approach is vulnerable to the so-called variations objection: if moral status is based on the possession of a property that confers value, or worth, on its holder, how come that those who hold that property to a higher/lower degree do not have a superior/inferior moral status (Arneson 1999, p. 107)? For instance, if we believe that moral status is grounded in one's capacity for autonomy, then why do we not assign superior/inferior moral status to those who hold this capacity to a higher/lower degree?

A plausible way of breaking through the state of deadlock that the search for the basis of moral equality seems to have reached is to explore an alternative avenue for the justification of moral equality: to ground moral equality we need not, and should not, look for a property that a certain range of beings possess equally; rather, we should focus on the wrongness of treating others as inferiors. Call this the relation-first approach to the question of the basis of moral equality. By grounding moral equality in the rejection of treating others as inferiors, rather than in the equal possession of the same status-conferring property, the relation-first approach seems to offer a convincing way to reject the variations objection.

This paper, however, argues that relation-first approach should be rejected for it gives rise to implausible normative prescriptions and it is unable to account for the idea that a range of beings has equal fundamental rights. Furthermore, such a critique will also clarify why the property-first approach still represents the most promising way of justifying the commitment to moral equality.

Even if some have pointed in this direction, ${ }^{2}$ the only fully fletched version of the relation first approach can be found in Andrea Sangiovanni's recent book Human Dignity without Humanity: Moral Equality, Respect and Human Rights ${ }^{3}$; for this reason, this paper will mainly focus on his account. This, however, does not mean that the contributions of this paper are exclusive to Sangiovanni's view, for its most evident problems generalise to the relation-first approach as such; therefore, anyone who wants to pursue this approach will have to overcome the difficulties that this paper identifies.

The paper is structured as follows: section 1 introduces Sangiovanni's view in more detail; section 2 argues that even if the relation-first approach can indeed avoid the variations objection by postulating a duty not to treat others as inferiors, to ground moral equality in such a duty may give rise to implausible conclusions; section 3 examines the conceptual relation between the ground of moral equality and its justification. In particular, I argue that a fundamental rights justification (henceforth, FRJ) - namely: the kind of justification that can vindicate the idea that a range of beings has equal fundamental rights - is only compatible with property-first accounts. This, I suggest, reveals an internal inconsistency in Sangiovanni's view

\footnotetext{
${ }^{1}$ For some prominent property-first accounts, see Ian Carter (2011), John Rawls (1971, pp. 504-512) and Bernard Williams (1973, pp. 230-249).

${ }^{2}$ See, for example, Avishai Margalit (1996, ch. 6) and, to a lesser extent, Anne Phillips (2015, ch. 1).

${ }^{3}$ All references without any indication of author and year of publication are to Sangiovanni (2017).
} 
and, more importantly, it entails that the relation-first approach in general does not have the theoretical resources to capture the most fundamental aspect of the question of moral equality.

This paper concludes that, despite its initial appeal, relation-first approach fails to provide a persuasive answer to the question of the basis of moral equality. Property-first views, whatever problems they encounter, are still more viable in principle.

\section{A Relation-First Account: Sangiovanni's View}

Sangiovanni's account of moral equality rests on a crucial distinction between two different kinds of moral statuses: basic moral status and equal moral status. The former is defined as 'a being's moral standing to be treated only in ways that we could justify from a common perspective' (p. 61); whereas, the latter 'refers to a being's moral claim to be treated as an equal' (p. 61). To understand Sangiovanni's view, it will be important to analyse what respectively grounds these two moral statuses. Let me address them in turn.

Sangiovanni's argument in favour of basic moral status can be summarised as follows:

1) A being has basic moral status when it matters in its own right and for its own sake;

2) A being matters in its own right and for its own sake only when things matter to it;

3) Only when a being has a conscious evaluative stance on the world do things matter to it;

4) Therefore, a being that has a conscious evaluative stance on the world has basic moral status (p. 65).

Sangiovanni's argument for the ground of moral equality is more complex. Sangiovanni's main contention is that moral equality is grounded in 'the wrongness of treating another as inferior' (p. 4); however, few would claim that, other things being equal, all those interactions which are based on a hierarchical structure are, by definition, wrong: it would be very odd, for example, to maintain that orchestras should be abolished insofar as there is a hierarchy between conductor and others; or, that a professor wrongs a student because she does not consider her as having an equal professional status. Hence, the question is: 'what is to treat someone as a moral unequal, as inferior in that sense, and why is it wrong?' (p. 73, emphasis in the original).

To answer this question, Sangiovanni examines five paradigmatic ways of treating others as inferiors: 1) dehumanisation; 2) infantilisation; 3) objectification; 4) instrumentalisation; 5) stigmatisation (p. 74). What fundamentally characterises these types of actions as wrong qua violation of equal moral status, Sangiovanni explains, is social cruelty, which is defined as 'the unauthorized, harmful, and wrongful use of another's vulnerability to attack or obliterate their capacity to develop and maintain an integral sense of self' (p. 76, emphasis in the original). ${ }^{4}$ Accordingly, Sangiovanni contends that treating someone as an inferior is wrong when and because it involves social cruelty, the wrongness of which lies in the fact that it attacks, or obliterates, the capacity to develop and maintain an integral sense of self, whose intrinsic value stems from its being a constitutive part of 'our enjoyment of the most important goods' (p.82).

\footnotetext{
${ }^{4}$ This form of cruelty, it is important to note, is distinguished from cruelty in its most general sense (henceforth, cruelty simpliciter) which Sangiovanni describes as 'the unauthorized and wrongful use of another's vulnerability to cause severe harm or suffering' (p. 75). I will return to the cruelty simpliciter/social cruelty distinction below.
} 
In this sense, then, 'inequality is prior to equality' because 'our commitment to moral equality is explained by or grounded in the rejection of inferiorizing treatment as socially cruel (rather than the other way around)' (p. 103, emphasis in the original). To put it differently, the core idea of the relation-first approach can be expressed as follows: we should not refrain from treating people as inferiors because they are equals; instead, we should treat them as equals because it is wrong to treat them as inferiors.

This Negative Conception of moral equality (p. 112), Sangiovanni argues, allows us to avoid the variations objection by embracing it. It is worth quoting him at length.

On my view, possession of a capacity to develop and maintain an integral sense of self does not give its possessor a higher worth. Rather, the possession of such a capacity makes us vulnerable to certain kinds of harm, and it is the rejection of these kinds of harm - namely, social cruelty - that trigger the need for a very specific kind of respect, which I have referred to as opacity respect ${ }^{5}$ (as a way of protecting people from the harm to which they are vulnerable). So, on my view, the third-party duties, and hence the character of the rights, will vary according to people's vulnerability, and hence according to the particular nature of their relationships to others, not according to their worth. (pp.

104-105, emphasis in the original)

Property-first accounts ground moral equality in the equal possession of a status-conferring property which confers value on its holder; consequently, as many have observed, these accounts have a hard time explaining why the variations above the moral status-threshold should not be morally relevant. Moreover, it is also unclear how property-first accounts can set the moral status-threshold in a non-arbitrary way. How much of a certain property does one have to hold in order to be deemed to have moral status (Arneson 2015)? One may think that any answer to this question is doomed to rest on arbitrary reasons. Call this the arbitrariness objection.

By contrast, the relation-first approach recommends us to stop searching for a property which bestows value, or worth, on its holder; rather, the basis of moral equality is to be found in the wrongness of treating others as inferiors. To put it another way, relation-first views start from the wrongness of an action rather than the possession of a status-conferring property. In particular, as we have seen, Sangiovanni's account states that treating others as inferiors is wrong when and because it involves social cruelty, for this would result in an attack on, or obliteration of, our capacity to develop and maintain an integral sense of self. This, Sangiovanni argues, has two important implications: first, the relation-first approach need not worry about the level of capacity one has to possess in order to have moral status; hence, relation-first accounts are not vulnerable to the arbitrariness objection (p. 106). Second, and more importantly, one's possession of a property plays a completely different role in his view: it does not confer any value on its possessor; rather, it makes her vulnerable to a specific wrong. Accordingly, this allows us to embrace the variations objection: the more someone is vulnerable to social cruelty, the more duties others have towards her. Equal moral status consists in having the right not to be treated in a socially cruel manner; in this sense, all those who can be treated in such a way are moral equals. What the correlative duty of respect requires, however, depends on how vulnerable to social cruelty one is (p. 104).

\footnotetext{
5 The notion of opacity respect has first been introduced by Carter (2011). The differences between Sangiovanni's and Carter's accounts of opacity respect are not relevant for the purposes of this paper.
} 
All in all, the relation-first approach proposes an ingenious way of looking at the question of the basis of moral equality; by starting from the wrongness of treating others as inferiors, relation-first views appear to be able to reject those objections that greatly undermine propertyfirst accounts.

\section{The Relation-First Approach and the priority Question}

In a nutshell, Sangiovanni contends that moral equality should be grounded in the rejection of social cruelty. In this section, I grant the assumption that we have a duty to refrain from treating others with social cruelty, but I want to cast some doubt on whether grounding moral equality in such a duty is plausible.

To introduce the problem at hand, it will be necessary to say something more about the roles that an account of moral equality is supposed to perform.

First of all, it should be observed that the principle of moral equality includes two different questions: the question of moral status and the question of equal moral status. ${ }^{6}$ The former determines the range of subjects who are entitled to a specific kind of treatment and should shed some light on what kind of treatment the beings that have moral status are entitled to. The latter, instead, tells us whether there is a group of beings, whose moral status is equal and, therefore, are entitled to equal treatment. In other words, an account of moral equality should ascertain whether, for example, a dog and a person have moral status - that is, whether they are entitled to a certain treatment; what the possession of moral status(es) entails - that is, what kind of treatment they are respectively entitled to; and, finally, whether their moral status is equal - that is, whether they are entitled to equal treatment.

The principle of moral equality, then, has a non-comparative as well as a comparative component. In this section, I will examine an aspect of the latter; in particular, I will focus on what I call the priority question. Suppose that there is an action $\mathrm{X}$ that must be done to either $\mathrm{A}$ or B. How do we decide whether X should be done to A or B, other things being equal? Typically, this seems a question to which a plausible account of moral equality should be able to provide a convincing answer.

For instance, many would contend that if we have to choose whom to save between a person and a dog we have a duty to save the former, other things being equal. This is because, many believe, a person is more valuable than a dog (or, equivalently, the former has a higher moral status than the latter). This intuition is at the core of property-first accounts which can justify this claim by pointing to the fact that persons have a superior moral status than dogs in virtue of the fact that the former hold a more valuable status-conferring property than the latter. $^{7}$

Now, it should be clear that the relation-first approach cannot similarly account for this claim insofar as it denies that there is any status-conferring property which confers value upon its holder. How, then, does the relation-first approach answer the priority question?

One may believe that relation-first accounts can appeal to the seriousness of the wrongs at stake. Take the following case. Suppose that Jack must wrong one between John and John's

\footnotetext{
${ }^{6}$ In this paragraph "moral status" and "equal moral status" are not understood as two different kinds of moral statuses, like in Sangiovanni's view, but as two different aspects of the principle of moral equality.

${ }^{7}$ Kant's account which finds the basis of moral equality in the capacity for autonomy (Kant 2002, p. 54) and Rawls's view which, similarly, suggests that equal moral status should be grounded in the capacity for moral personality (Rawls 1971, pp. 504-512) are two prominent examples.
} 
dog, Spot. ${ }^{8}$ The proponents of the relation-first approach may suggest that Jack should decide by weighing up the seriousness of the different wrongs at stake. In so doing, Jack may realize, for example, that wronging John will result in an act of social cruelty, while wronging Spot will constitute an act of cruelty simpliciter. And, since it seems reasonable to affirm that social cruelty is a more serious wrong than cruelty simpliciter - insofar as the former does not only cause harm or suffering but it also attacks, or obliterates, the capacity to develop and maintain an integral sense of self (p. 76) - then Jack should wrong Spot. Hence, the relation-first approach does seem able to provide an answer to the priority question by appealing to the seriousness of the wrongs, rather than the value of the beings, at stake. But is this a plausible answer?

One may think that this is simply not the kind of response we are looking for. Imagine that Jack has to justify his choice to John. He would probably say something along these lines: "John, I have chosen to wrong Spot not because I think that you are more valuable than a dog, but simply because I think that wronging you would have involved a more serious wrong than wronging a dog". I do believe that there is something odd with this answer: what Jack seems to be missing here is that it is not just wrong to act in a socially cruel manner per se; rather, Jack should recognize John as worthy of not being treated in such a way in virtue of the kind of being he is. It is not only about the seriousness of the wrong that is committed, but also about the value of the subjects that are wronged. This, however, is precisely what relation-first accounts deny; accordingly, I do not want to press too hard on this point here. What I want to stress, instead, is that even if we concede that this line of response to the priority question is successful in cases in which different wrongs are at stake, it seems to give rise to disturbing implications in cases in which beings with different moral statuses are vulnerable to the same kind of wrong.

In this respect, it should first be noticed that it seems implausible to hold that those beings that have the capacity to develop and maintain an integral sense of self can only suffer from social cruelty. Sangiovanni agrees for he discerns two different kinds of inferiozing attack: a mere offence (or, insult) and social cruelty. What fundamentally distinguishes the two is that only the latter is seen as 'a part of a systematic societal pattern' to undermine one's social relations with others (p. 96), or 'an attempt to undermine one or more of the structural conditions for maintaining and developing one's integrity' (p. 96). But the crucial question for our purposes is the following: can those beings that have the capacity to develop and maintain an integral sense of self be also vulnerable to cruelty simpliciter?

Surprisingly, Sangiovanni leaves the distinction between social cruelty and cruelty simpliciter fairly vague; why this may be problematic clearly emerges, for instance, from his discussion of a paradigmatic case of social cruelty: rape. Sangiovanni observes that ' $r$ rape is not only an incursion in one's bodily integrity, like breaking someone's arm. It is, more importantly, an incursion in one's capacity to develop and maintain an integral sense of self' (p. 85). But if there is a distinction between rape and breaking one's arm and the former is a violation of one's capacity to develop and maintain an integral sense of self - namely, an act of social cruelty - one may plausibly think that the latter is just a case of cruelty simpliciter, at least in some circumstances. If this is true, how do we decide whether to break John's arm or Spot's paw? Since, ex hypothesi, the wrong at stake is the same, and the beings' value cannot be taken into account, then Sangiovanni seems to be committed to the following answer: we should flip a coin, other things being equal. This, I submit, is a conclusion that few would be happy to accept.

\footnotetext{
${ }^{8}$ Whether the relation-first approach can justify the claim that Jack can wrong John or Spot will be discussed in the next section.
} 
Two implications can be drawn from this discussion. First, Sangiovanni's account seems to run against a dilemma: on the one hand, if the social cruelty-threshold is set too low, then any kinds of cruel act must be understood as an attack to one's capacity to develop and maintain an integral sense of self; on the other hand, if the social cruelty-threshold is set too high, then those beings that have the capacity to develop and maintain an integral sense of self might seem to be also vulnerable to cruelty simpliciter. This suggests that Sangiovanni is wrong to claim that, contrary to property-first accounts of moral equality, the relation-first approach is not subject to the arbitrariness objection (p. 106). The latter does not seem to score better than the former in this respect.

Second, as the discussion on rape seems to suggest, Sangiovanni rightly acknowledges that the first horn of the dilemma is implausible, so he chooses the second horn. However, this shows why grounding moral equality in the wrongness of being treated as inferior rather than in the equal possession of a property might be problematic: if this is the only factor that can determine our decision, in situations in which both a person and a nonhuman animal are equally vulnerable to the same kind of cruelty, but social cruelty is not involved, then we have no reason to favour the former over the latter, other things being equal. In other words, if we ground moral equality in the wrongness of its violation rather than in the value of the beings at stake, then we cannot see that the seriousness of the wrong does not only depend on the nature of the wrong itself but also on the nature (or, better, the value) of the beings which are wronged - that is, we cannot see that the same wrong done to different beings should be treated differently.

How could Sangiovanni attempt to rescue the relation-first approach from this objection?

Sangiovanni may want to respond that the nature of the wrong can be determined by the nature of the being: breaking one's arm means something different to a person than to a dog. Hence, even when the same wrong is at stake, the nature of the being which is to be wronged can define the seriousness of the wrong. So, suppose again that both John and Spot could be treated cruelly. What Sangiovanni may suggest is that since it is worse for John than for Spot to be treated cruelly, then Jack has a reason, which has nothing to do with John's and Spot's moral value, or worth, to wrong the latter. Therefore, the relation-first approach appears to have the theoretical resources to provide a convincing answer to the priority question even in cases in which the same wrong is at stake.

While I believe that it is correct to hold that the nature of the wrong can be determined by the nature of the being which is subject to the wrong, I doubt that one can appeal to this line of reasoning to rescue the relation-first approach. This is because either this argument is grounded in the presumption that a person has a superior moral status than a dog - breaking a person's arm is a different and more serious wrong than breaking a dog's paw because the former is more valuable than the latter; however, it should be clear, this is precisely what we cannot assume according to relation-first views. Or, alternatively, one may say that the reason why breaking one's arm means something different to a person than to a dog lies in the different capacities that they respectively possess: while a dog can only feel the pain that is generated by a cruel act; a person, in virtue of her developed sense of self, can also reflect upon its meaning and its cause. If this is the case, however, even if it is not, strictly speaking, the value that comes first, it is still a property, not the wrong, that does so; and, this is what Sangiovanni, and any relation-first account more in general, wants to avoid. For this reason, I conclude that this response cannot rescue Sangiovanni's relation-first account from my objection to its answer to the priority question.

At this point, Sangiovanni may contend that my example is misleading. This is because on the one hand, despite what he seems to suggest in his discussion on rape as an act of social cruelty, Sangiovanni may want to argue that breaking one's arm is indeed a case of social 
cruelty; on the other hand, he may observe that dogs, as highly social animals, do not merely perceive pain but they can also feel resentment against the perpetratour of a cruel act; hence, it is reasonable to maintain that dogs may be also vulnerable to social cruelty. If this is true, then dogs and human beings have equal moral status; and, it may simply be our speciesist-biased intuitions that tell against Jack's decision to flip a coin to decide whether to break John's arm or Spot's paw.

This answer, I suspect, will not get Sangiovanni's view very far. Let us slightly revise our original example. Jack has now these two options: breaking John's arm or breaking a wing of John's canary, Tweety. Since no one, I believe, would maintain that Tweety is vulnerable to social cruelty, then the question is the following: is breaking John's arm necessarily an act of social cruelty? Suppose that unless Jack commits one of the two wrongs, five persons will die. Jack, then, apologetically explains to John that he does recognise and value his capacity to develop and maintain an integral sense of self. He has no intention whatsoever to use his vulnerability to attack, or obliterate, his capacity. Furthermore, independently of Jack's intention, it is hard to see how such an act would constitute an example of social cruelty, given that it is neither part of a societal pattern, nor does it attempt to undermine John's integrity. This, then, seems a case in which two beings with different moral statuses are vulnerable to the same kind of wrong, and social cruelty is not involved; therefore, according to the relation-first approach, there is nothing to be said in favour of breaking Tweety's wing rather than John's arm. Once again, Jack should toss a coin. ${ }^{9}$ All in all, then, Sangiovanni's view does not seem to be able to provide a persuasive answer to the priority question unless he implausibly stipulates that those beings that have equal moral status are only vulnerable to social cruelty.

At this point, it might be helpful to summarise and elaborate on what has been argued so far in order to see how the problems that undemrine Sangiovanni's view generalise to the relationfirst approach as such.

According to the relation-first approach, one's moral status depends on the kind of wrong one is vulnerable to: so, John has equal moral status because he can be treated as an inferior, while Spot has only basic moral status because it cannot be treated in such a way. One's moral status is independent of one's moral value, or worth; hence, John is not more valuable than Spot because he has equal moral status while Spot has only basic moral status. As Sangiovanni points out, moral status is not understood as one's position in a specific hierarchy (pp. 100101). However, this move, I have pointed out, seems questionable when it comes to the priority question: how can we decide what to do in cases in which beings that have equal moral status and those that have basic moral status are equally vulnerable to the same kind of wrong? By grounding moral equality in the rejection of a specific wrong, relation-first views are committed to holding that different beings who are subject to the same wrong must be

\footnotetext{
${ }^{9}$ Two points may be worth noting. First, one may observe that this is not a case of cruelty simpliciter: one may maintain that Jack would simply inflict pain on John or Twetty without actually being cruel to them. Hence, this is not a case in which beings with different moral statuses are both vulnerable to cruelty simpliciter. This, however, does not undermine the validity of my point which does not rest upon the kind of wrong to which John and Twetty are both vulnerable, but on the possibility for them to suffer from the same wrong in a situation in which social cruelty is not involved.

Second, one may note that in the example at hand there is no wrong at stake in the first place: after all, Jack must save five persons who are in danger; and if doing so requires him to breaking either John's arm or Tweety's wing, this does not entail that he would wrong them. Be as it may, the priority question asks us to decide whether an action X should be done to either A or B, other things being equal: the (im)permissibility of the action in question is irrelevant to the plausibility of our answer.
} 
treated equally. This, however, as the example of Jack and Spot shows, gives rise to disturbing normative prescriptions.

Finally, it should be noted that what is problematic is not only the answer that relation-first views give to the priority question; what is also objectionable, I think, is the blindness of these views to factors that are morally relevant, namely: the beings' moral value. So, admittedly, one may think that it is right for Jack to toss a coin to decide whether John or Spot should be treated cruelly, other things being equal; what I am claiming, however, is that whether this is true or not should also depend on John's and Spot's moral value. It seems questionable to maintain that what can, or should, be done to John and Spot exclusively depends on the nature of the action in question, rather than also on their (possibly different) moral value. In short, what is objectionable is not only the conclusion that the relation-first approach entails when answering the priority question in cases in which the same wrong is at stake - i.e., equality among persons and nonhuman animals - but also how this is reached - i.e., the insensitivity to morally relevant factors.

In conclusion, to reject the variations objection, the relation-first approach invites us to start from the wrongness of the action, so that one's moral status can be detached from one's moral value, or worth. In this section, I attempted to show that even if such an approach can avoid the variations objection, this comes at the cost of impoverishing our moral theorizing by failing to capture morally relevant factors and, consequently, providing an account of moral equality which has implausible implications as to the priority question when the same wrong is at stake. Anyone taking this approach will face this strong challenge, at least.

\section{The Relation-First Approach and a Fundamental Rights Justification (FRJ): An Impossible Marriage}

Typically, the question of the basis of moral equality is associated with the justification of equal fundamental rights to a certain range of beings (Carter 2011, p. 539; Rawls 1971, p. 504; Sangiovanni 2017, pp. 101-102): in virtue of what can A and B be said to have equal fundamental rights? This is the question that an account of moral equality is usually expected to answer. Accordingly, it seems reasonable to maintain that an account of moral equality should be able to provide what I have called a fundamental rights justification (FRJ).

This section examines the conceptual relation between the ground of moral equality and its justification; in particular, I argue that a FRJ is only compatible with property-first accounts. This has two important implications: first, it suggests that Sangiovanni's view may be internally inconsistent: this is because on the one hand Sangiovanni wants to offer a FRJ (pp. 101-102) but, on the other hand, he maintains that moral equality should not be grounded in the equal possession of a status-conferring property that confers equal value upon its holders; second, more generally, this entails that relation-first approach is not a serious contender of property-first accounts for the justification of moral equality because it does not have the theoretical resources to capture its most fundamental aspect.

To defend these two claims, I proceed as follows: first, I clarify the concept of a FRJ; second, I investigate what, according to Sangiovanni, grounds the duty to refrain from acting in a socially cruel manner; finally, I show that relation-first accounts cannot ground a FRJ.

To elucidate the concept of a FRJ, it will be instructive to introduce the distinction between directed and undirected duties. Take these two different duties: (A): "Matthew has a duty to help Lara"; (B): "Matthew has a duty to help the world's needy". (A) and (B), respectively, 
represent two standard instances of directed and undirected duty. The main difference between the two consists in the fact that only the former, but not the latter, is owed to someone in particular. The direction of duties is relevant for, at least, the following two reasons: first, 'directed duties are at the heart of rights' (Cruft 2013, p. 201): Matthew's duty to help Lara entails that Lara has a claim-right against Matthew to be helped. ${ }^{10}$ On the contrary, from the fact that Matthew has a duty to help the world's needy it does not necessarily follow that they have a claim-right against Matthew to be helped. ${ }^{11}$ Second, this means that only violations of directed duties entail wronging, whereas violations of undirected duties imply wrongdoing (May 2012, p. 113) ${ }^{12}$ : this is because if Matthew does not help Lara, then Matthew wrongs her for he has violated her right to be helped; instead, if Matthew does not help the world's needy, Matthew is simply doing something wrong, but he is not wronging anyone in particular, insofar as no one's right has been violated.

The triadic relation between directed duties, rights, and wronging is well explained by F. M. Kamm: "[f]or to claim that you have a right to be helped by me ... is to claim that I have a directed duty to you (as subject), so that if I do not act I would not only be acting wrongly, I would also wrong you' (Kamm 2007, p. 244). A FRJ, then, is the kind of justification which can account for the idea that if $\mathrm{A}$ and $\mathrm{B}$ are moral equals, then $\mathrm{A}$ and $\mathrm{B}$ have equal fundamental rights.

At this point, the question that needs to be addressed is the following: what kind of ground is compatible with a FRJ?

To begin with, few, I think, would deny that property-first accounts can ground a FRJ. As we have seen, this approach starts from a property, which bestows value on its holder. More specifically, the core idea is that in virtue of the possession of a specific property, B is valuable and B's value generates duties on A to respect B's rights. To put it differently, B's value entails that $\mathrm{A}$ has directed duties to $\mathrm{B}$, that is, duties that are owed to $\mathrm{B}$ for B's own sake, regardless of any further consequences.

Can the relation-first approach similarly account for a FRJ? As has already been discussed, this approach states that equal moral status should be grounded in the rejection of moral inequality. In particular, Sangiovanni's account maintains that the basis of moral equality is to be found in the rejection of social cruelty. In the previous section, I have suggested that even if we have a duty to refrain from acting in a socially cruel manner, to ground moral equality in such a duty gives rise to implausible conclusions. I now want to examine what grounds our moral imperative not to be socially cruel.

A natural way to start our enquiry is to recall Sangiovanni's definition of social cruelty: 'the unauthorized, harmful, and wrongful use of another's vulnerability to attack or obliterate their capacity to develop and maintain an integral sense of self' (p. 76, emphasis in the original). To maintain that social cruelty is wrong insofar as it constitutes an attack on, or an obliteration of, one's capacity to develop and maintain an integral sense of self, however, is hardly enough to ground a prohibition against social cruelty: something more must be said on why attacking or obliterating one's capacity to develop and maintain an integral sense of self is wrong. And, here the wrongness seems to lie in the fact that such a capacity is extremely valuable to, or for,

\footnotetext{
${ }^{10}$ The correlativity thesis has first been formulated by W. N. Hohfeld (1913). A detailed analysis of the relation between directed-duties and rights is beyond the scope of this paper. For our purposes, it will be sufficient to say that all rights entail directed duties, but the opposite is not true.

${ }^{11}$ Alternatively, one may say that while Matthew has a duty of justice to help Lara, he only has a duty of charity, or beneficence, to help the world's needy.

${ }^{12}$ For an illuminating discussion on the difference between wronging and wrongdoing, see Michael Thompson (2004).
} 
us; indeed, as we have seen in section 1, Sangiovanni maintains that the capacity to develop and maintain an integral sense of self is intrinsically valuable because it is a constitutive part of all the most important human goods (p. 81). In short, then, Sangiovanni contends that 'the individual interests underlying our sociability [that is, our capacity to develop and maintain an integral sense of self] are so important that they ground a set of third-party duties not to treat with inferiorizing social cruelty' (p. 101).

Accordingly, in a more formal manner, Sangiovanni's argument for the ground of the rejection of social cruelty can be reconstructed as follows:

1. 'Social cruelty is (pro tanto) wrong because it is a harmful attack on or obliteration of another's capacity to develop and maintain an integral sense of self' (p. 76, emphasis in the original);

2. An integral sense of self is valuable because it is a constitutive part of all the most important human goods (p. 81);

3. Therefore, A has a directed duty to refrain from treating B with social cruelty because this would violate something of great value to, or for, B.

The problem with this line of reasoning, I argue, is that (3) is not sufficient to yield a normative prescription: it is unclear why from the fact that $\mathrm{B}$ has an interest in $\mathrm{X}$ - that is, from the fact that $\mathrm{X}$ is of great value to, or for, $\mathrm{B}-$ it follows that $\mathrm{B}$ has a right to $\mathrm{X}$ against $\mathrm{A}$.

To see this, consider the following case of social cruelty. Being the chief executive officer of a big company which makes millions of dollars a year, Thomas has great power over his employees, and he uses his position to demean and hurt his personal assistant, Susan, by, among other things, using abusive language and sending her offensive emails. What we want to understand is why Thomas failed in his directed duty not to be socially cruel to Susan. As we have seen, Sangiovanni argues that this is because Thomas's behaviour resulted in an attack on, or obliteration of, something that is of great value to, or for, Susan - i.e., her capacity to develop and maintain an integral sense of self. However, what I am suggesting is that (i) " $\mathrm{X}$ is of great value to, or for, B" does not entail that (ii) "A has a directed duty to B to X". Thomas, then, can respond to Sangiovanni's accusation by pointing out that it is not enough to show that his actions violated something that is of great value to, or for, Susan; it must also be shown that Susan is valuable for her own sake to demonstrate that he owed something to her in the first place. In other words, what I am claiming is that while what is of great value to, or for, Susan may be a good indicator of the kinds of rights that Susan can have, it cannot be cited as a reason for why Susan has, or can have, a right in the first place. To paraphrase J. D. Velleman, what is good for, or what is of interest to, Susan, it need not matter unless Susan matter (Velleman 1999, p. 611).

Sangiovanni's criticism of Velleman's property-first account becomes relevant to our discussion here. Very briefly, here is how Sangiovanni reconstructs Velleman's (1999) argument:

A. We believe that either our good or others' good matters, therefore we claim that this should be the object of concern;

B. A person's good matters if and only if a person matters for her own sake;

C. The value of the former is conditional on the value of the latter;

D. Therefore, (i) the person has value independently of what has value for her; (ii) the value of the former is incommensurable with the value of the latter; and, (iii) the value of the former is higher than the value of the latter. (p. 44) 
To begin with, it should be noted that I need not defend Velleman's argument per se; accordingly, I need not take a stance on (D). ${ }^{13}$ For our purposes, it is important to assess Sangiovanni's criticism of (B).

Now Sangiovanni claims that 'the argument only succeeds by assuming that there must be a bearer of value - a person, understood as a being with a rational nature - separate from the particular cares and concerns that make up a human life and for the sake of which we act' (p. 45 , emphasis in the original). Nothing, however, requires us to assume that 'our rational nature as such can be bearer of value apart from our flourishing' (p. 45).

If Sangiovanni's objection is that nothing in Velleman's argument requires us to accept that our rational nature is the specific interest-independent value that grounds the value of our flourishing, then he seems to me right on this point. This, however, does not concern us here. What is at stake is not whether our rational nature in particular can ground the value of our flourishing, but whether the latter, which is interest-relative, must be based on an interestindependent value in general - we are not questioning what interest-independent value can ground the value of our flourishing, but whether such a value must be presupposed. But if this is the case, I do not see how we can avoid making this assumption: if A owes to B to do X, there must be something about $\mathrm{B}$ for its own sake which generates a duty on $\mathrm{A}$ to do $\mathrm{X}$. There is a leap from " $\mathrm{X}$ is of great value to, or for, $\mathrm{B}$ " to " $\mathrm{B}$ has a right to $\mathrm{X}$ " that is in need of justification. In particular, it is not clear where the normative force comes from: unless Thomas has a reason to be concerned with Susan for her own sake in the first place why does he owe to Susan to respect, or promote, something that is of great value to, or for, her (e.g., not being sexually harassed)? To this question, I argue, only property-first accounts can provide an answer.

Sangiovanni's view, then, runs against a dilemma: either he grounds moral equality in the equal possession of a specific property, but this means that his view is just another version of the property-first approach, which is the approach to moral equality that Sangiovanni rejects; or, he grounds moral equality in a general duty not to treat others as inferiors, but this is inconsistent with a FRJ, which is the kind of justification that, Sangiovanni believes, an account of moral equality should be able to provide. Whichever horn of the dilemma he chooses, Sangiovanni seems to fail to do what he set out to do.

Let me conclude by briefly analysing how a FRJ is fundamentally incompatible with the relation-first approach. To do this, it will be instructive to examine what I am not claiming. I am not claiming that A can have a duty to satisfy B's interests if, and only if, A has reasons to care about B for its own sake.

After all, it seems undeniable that A may have a duty to respect, or promote, B's interests even if $\mathrm{A}$ has no reasons to care about $\mathrm{B}$ for its own sake. So, for example, one may say that social cruelty is wrong because it attacks or obliterates something extremely valuable to B; however, A's duty not to be socially cruel to B does not have to presuppose B's value, or worth, insofar as it can be grounded in a consequentialist imperative to refrain from bringing about a state of affairs which involves social cruelty. Alternatively, we can also imagine a deontological view which, similarly, holds that the rejection of social cruelty is grounded in the wrongness of causing a state of affairs which involves social cruelty; this duty, however, would not require minimising the level of social cruelty, but it would command not to treat anyone in a socially cruel manner yourself.

${ }^{13}$ For a Kantian account which rejects (D), see Thomas Hill (1991, pp. 93-95). For an instructive criticism of Velleman's view, see Jeff McMahan (2002, pp. 473-485). 
What must be noted is that while both these versions of the relation-first approach do offer a reason as to why A has a duty not to violate what is of great value to, or for, B which is independent of B's value, or worth, neither of them is compatible with a FRJ. Let me explain.

As to the consequentialist version of this justification, it is easy to see why this is the case: A's claim not to be treated as inferior is conditional upon whether not treating A in a socially cruel manner will lead to a state of affairs in which there will be no social cruelty (or, at least, the level of social cruelty will be lower than what would have been if A had been treated cruelly). But this, as many commentators noted, is not what a right is about: for A to have a right not to be treated socially cruelly A's claim to such a treatment must be respected independently of its social consequences. ${ }^{14}$

The deontological version of the relation-first approach is equally unable to account for a FRJ. To see this more clearly, H. L. A. Hart's discussion of the Ten Commandments might be instructive (Hart 1955). Hart points out that if, in violating one of the Ten Commandments, A harms B, it is wrong to conclude that A has thereby violated B's rights, since it would be misleading to maintain that $\mathrm{B}$ had any rights against $\mathrm{A}$ in the first place. This is because, in this scenario, A's duties are owed to God; B is only the object, but not the subject - or, alternatively, B is only the focus but not the source (Buchanan 1987, p. 52) - of A's duties, insofar as it is not for the sake of B that A has a duty not to harm her. Hence, in harming B A is wronging God, but she is not wronging B (Hart 1955 , p. 182). Similarly, if what grounds the rejection of social cruelty is merely the fact that A should not treat anyone with social cruelty herself, then if $\mathrm{A}$ is socially cruel to $\mathrm{B}$, she is not wronging B - that is, she is not violating B's rights - but she is simply doing something wrong.

All in all, it seems reasonable to maintain that there might be versions of the relation-first approach that can justify A's duty not to violate something that is of great value to, or for, B without having to presuppose B's value; however, neither of these versions can justify A's directed duty to B. Therefore, these accounts cannot ground a FRJ, namely: they cannot vindicate the idea there is a range of beings that has equal fundamental rights. But this, as we have seen, is exactly what we want from an account of moral equality. For this reason, I conclude that the relation-first approach does not offer a persuasive justification of the principle of moral equality.

\section{Conclusion}

In this paper, I have argued against the relation-first approach to the basis of moral equality. In particular, I have first argued that even if we have a duty to refrain from treating others as inferiors, to ground moral equality in such a duty is not plausible because it leads to disturbing conclusions as to the priority question - i.e., equality among persons and nonhuman animals (at least) in cases in which the same wrong is at stake. Second, I have noted that the question of moral equality is usually concerned with the justification of equal moral status, understood as a bundle of equal fundamental rights. However, I have shown that the relation-first accounts do not have the theoretical resources to account for a FRJ. This, I have concluded, suggests that this approach is not a promising rival to property-first accounts for the justification of the principle of moral equality.

\footnotetext{
${ }^{14}$ To be sure, this is not to say that it may never be permissible to infringe A's rights if this is necessary to avoid severe social consequences. This is a complex issue that cannot be adequately addressed here. For our purposes, it is sufficient to point out that the idea of status as a bundle of fundamental rights, which are not justified on the basis of social consequences, is fundamentally in contradiction with a consequentialist framework.
} 
Property-first accounts may have not yet succeeded in providing a definitive answer to the question of the basis of moral equality ${ }^{15}$; proponents of the relation-first approach, like Sangiovanni, then, suggest that we may have been looking at this question in the wrong way so far. This paper offers some reasons to believe that we should reject this suggestion: rather, we should just look harder.

Acknowledgements Previous versions of this paper have been presented at Manchester, Warwick, Stanford and Dresden. I thank all audiences for helpful feedback. From those occasions, I am particularly grateful to Miriam Ronzoni, Dana Howard, Barry Maguire, Avia Pasternak, and Andrea Sangiovanni. I would also like to thank Jonny Benson, Vittorio Gerosa, Valeria Ottonelli, and Federico Zuolo for discussions and comments on this paper. Finally, I owe a special debt of gratitude to Christian Schemmel and Liam Shields for their invaluable help.

Open Access This article is distributed under the terms of the Creative Commons Attribution 4.0 International License (http://creativecommons.org/licenses/by/4.0/), which permits unrestricted use, distribution, and reproduction in any medium, provided you give appropriate credit to the original author(s) and the source, provide a link to the Creative Commons license, and indicate if changes were made.

\section{References}

Arneson RJ (1999) What, if anything, renders all humans morally equal? In: Jamieson D (ed) Peter singer and his critics. Blackwell, Oxford, pp 103-128

Arneson RJ (2015) Basic equality: neither acceptable nor Rejectable. In: Steinhoff U (ed) Do all persons have equal moral worth?: on 'Basic Equality' and equal respect and concern. Oxford University Press, Oxford, pp 30-52

Buchanan A (1987) Justice and charity. Ethics 97(3):558-575

Carter I (2011) Respect and the basis of equality. Ethics 121(3):538-571

Christiano T (2015) Rationality, equal status, and egalitarianism. In: Steinhoff U (ed) Do all persons have equal moral worth?: on 'Basic Equality' and equal respect and concern. Oxford University Press, Oxford, pp 53-75

Cruft R (2013) Why is it disrespectful to violate rights? Proc Aristot Soc, CXIII 113(2):201-224

Hart HLA (1955) Are there any natural rights? The Philosophical Review 64(2):175-191

Hill TEJ (1991) Autonomy and self-respect. Cambridge University Press, New York

Hohfeld WN (1913) Some fundamental legal conception as applied in judicial reasoning. Yale Law J 23(1):16-59 Husi S (2017) Why we (almost certainly) not moral equals. J Ethics 21:375-401

Kamm FM (2007) Intricate ethics: rights, responsibilities, and permissible harm. Oxford University Press, New York

Kant I (2002) Groundwork for the metaphysics of morals. Yale University Press, New Haven and London Margalit A (1996) The Decent Society (N. Goldblum, trans.). Harvard University Press, Cambridge (MA) May SC (2012) Moral status and the direction of duties. Ethics 123(1):113-128

McMahan J (2002) The ethics of killing. Problems at the margins of life. Oxford University Press, Oxford Phillips A (2015) The politics of the human. Cambridge University Press, Cambridge

Rawls J (1971) A Theory of Justice. Harvard University Press, Cambridge (MA)

Sangiovanni A (2017) Humanity without Dignity. Moral Equality, Respect, and Human Rights. Harvard University Press, Cambridge (MA)

Thompson, M. (2004). What is to wrong someone? A puzzle about justice. In P. Pettit, S. Scheffler, S. M. \& R. J. Wallace (Eds.), Reason and value: themes from the moral philosophy of Joseph Raz (pp. 333-384). Oxford: Claredon Press

Velleman JD (1999) A right of self-termination? Ethics 109(3):606-628

Williams B (1973) Problems of the self. Philosophical papers 1956-1972. Cambridge University Press, Cambridge

Publisher's Note Springer Nature remains neutral with regard to jurisdictional claims in published maps and institutional affiliations.

${ }^{15}$ However, I believe that Carter's work is very promising in this direction (Carter 2011). For some criticisms of Carter's view, see, among others, Stan Husi (2017) and Thomas Christiano (2015). 